\title{
The Drug Regimen Prescribed for Sickle Cell Patients Attending a Clinic in Kumasi, Ghana, in a Period of One Year
}

\author{
Kwabena Nsiah', Alex Osei-Akoto ${ }^{2,3}$, Daniel Ansong ${ }^{2,3}$ \\ ${ }^{1}$ Department of Biochemistry and Biotechnology, College of Science, Kwame Nkrumah University of Science \\ and Technology, Kumasi, Ghana \\ ${ }^{2}$ Department of Child Health, College of Health Sciences, School of Medical Sciences, Kwame Nkrumah \\ University of Science and Technology, Kumasi, Ghana \\ ${ }^{3}$ Department of Child Health, Komfo Anokye Teaching Hospital, Kumasi, Ghana \\ Email: kwabena.kay.nsiah@gmail.com
}

Received 15 September 2014; revised 10 October 2014; accepted 10 November 2014

Copyright (C) 2014 by authors and Scientific Research Publishing Inc.

This work is licensed under the Creative Commons Attribution International License (CC BY).

http://creativecommons.org/licenses/by/4.0/

(c) (7) Open Access

\begin{abstract}
Objective: In order to manage the varied pathophysiological features of sickle cell disease (SCD), an array of drugs has to be used. The specific drugs used, however, depend on the locality. This study was aimed at finding out the drug regimen prescribed by clinicians to sickle cell disease patients who attended a Sickle Cell Clinic in Kumasi, Ghana. Method: The setting for the study is the Sickle Cell Clinic at the Komfo Anokye Teaching Hospital, Ghana, and a questionnaire was used as the study instrument. Information on drug prescription on each day of clinic visit was extracted from the medical records of the patients. Results: The drugs prescribed were "routine drugs" for SCD patients, analgesics, narcotics, anti-malarials, antibiotics, haematinics and miscellaneous drugs. The top ten commonly prescribed drugs were folic acid, diclofenac, ibuprofen, B-complex, routine drugs, artesunate/amodiaquin, paracetamol, penicillin $V$, amoxiclav and zincovit. Conclusion: Within the year, the drugs prescribed included those that could prevent vitamin and zinc deficiency due to continuing haemolysis, those that could mitigate the pain and inflammation from vaso-occlusion and reperfusion injury, as well as antibiotics to combat infections. Being a malarial-endemic region, prophylaxis with daraprim and symptomatic malaria fever therapy were common practices. This study has thus shown that the well-being of SCD patients in our typical tropical terrain, depends on haematinic vitamin/mineral supplements, anti-malarials, analgesics-anti-inflammatory, antipyretics and antibiotics.
\end{abstract}

\section{Keywords}

Sickle Cell, Drugs, Malaria, Pain, Analgesics

How to cite this paper: Nsiah, K., Osei-Akoto, A. and Ansong, D. (2014) The Drug Regimen Prescribed for Sickle Cell Patients Attending a Clinic in Kumasi, Ghana, in a Period of One Year. Open Journal of Blood Diseases, 4, 50-57. 


\section{Introduction}

Due to the instability of the mutant HbS which polymerises when deoxygenated to render the red cell non-deformable, SCD subjects are characterized by episodic vaso-occlusive crises, marked by ischaemia, reperfusion injury, inflammatory changes, vasculopathies and complications of organ damage [1] [2]. The accompanying changes are pain syndromes which could be acute, chronic or mixed [3] [4].

Thus, a SCD patient reports to a health care facility, with pain as the most common clinical problem [5], together with signs and symptoms like fever, jaundice, pallor, anaemia, coughs, etc. Vaso-occlusion is the outcome of dynamic combinations of abnormalities of haemoglobin structure and function, erythrocyte membrane integrity, erythrocyte density, endothelial activation, microvascular tone, inflammatory mediators and coagulation [6]. The pathophysiolgical events translate into clinical manifestations like anaemia and its sequelae, vasoocclusive crises, infection (from functional asplenia) and organ dysfunction [6].

The heterogeneity of the clinical expression of SCD patients [7] calls for careful examination by clinicians in order to arrive at definitive diagnoses. For any group of such patients being attended to, there would be differing diagnoses, which would require different therapeutic interventions. Hankin and Aygun [8] observed that the multifactorial nature of SCD required the use of drugs with different physiological targets. This study was therefore, aimed at finding out the drug regimen prescribed by clinicians to sickle cell disease patients who attended a Sickle Cell Clinic at the Komfo Anokye Teaching Hospital, Ghana, within a twelve-month period.

\section{Methods}

From October 2006 to date we have been undertaking studies on sickle cell patients. This present study focused on drug prescriptions to sickle cell patients between the ages of 5 to 20 years. On the day of recruitment into the study, following the examination by the attending clinicians, the subjects were grouped into either the crisis or steady state.

Each patient has a file in which the medical records are kept in the hospital, but are retrieved when patients report to the hospital for consultation. The relevant information for the preceding twelve months was extracted, including age, place of residence, the presenting clinical state, the number of previous visits and the clinical conditions during all the visits, likewise the drugs prescribed by the doctor.

\section{Results}

Using 92 SS females (61 in crisis and 31 in steady state), as a representation of the study group, Table 1 gives

Table 1. The most commonly prescribed drugs for 92 SS female SCD patients.

\begin{tabular}{|c|c|}
\hline Type of drug & Frequency \\
\hline Folic acid & 157 \\
\hline Diclofenac & 88 \\
\hline Ibuprofen & 77 \\
\hline Routine drugs & 80 \\
\hline Zincovit & 66 \\
\hline B-complex & 66 \\
\hline Paracetamol & 50 \\
\hline Plasmotrium & 42 \\
\hline Daraprim & 49 \\
\hline Amoxiclav & 47 \\
\hline Camoquin & 32 \\
\hline Artesunate & 27 \\
\hline Penicillin V & 12 \\
\hline Artesunate/amodiaquine & 11 \\
\hline Morphine & 12 \\
\hline Bencozinc & 15 \\
\hline Amoxicillin & 13 \\
\hline Ciprofloxacin & 12 \\
\hline
\end{tabular}


the list of 18 most commonly prescribed drugs. The females of the SS genotype were chosen as they made the highest number of visits, 346, within the study period. The SS males made 316 visits. The most frequently prescribed drug was folic acid; followed by diclofenac, then "routine drugs" and ibuprofen. The routine drugs, before the adoption of use of mosquito nets included folic acid, daraprim and penicillin $\mathrm{V}$, but where mosquito nets are used, daraprim prophylaxis is discontinued. It has to be pointed out that there were other drug combinations prescribed as routine drugs, such as folic acid/B-complex/daraprim or folic acid/zincovit/daraprim, depending on the clinician in attendance. Apart from the two main specialist pediatricians (D. A and A. O. A), there were other medical doctors, who came to assist quite often, particularly when the attendance to the clinic was high. Sometimes, the attendance could be as high as 150 patients in one clinic session.

The prescribed drugs could be classified based on their therapeutic effect or pharmacological action, and the frequency of prescription. Based on the therapeutic effect, the common drugs used fall under five major groups; analgesics/narcotics, anti-inflammatory, anti-malarials, antibiotics and vitamins/mineral supplements (Table 2). Apart from the drugs, one other supportive therapy was blood transfusion, given to severely anaemic patients who were admitted to the hospital. Only top-up or additive transfusion is used.

Based on frequency, we grouped the drugs into three; the most commonly prescribed in the previous 12 months (from ten times and above), the less frequently prescribed and the least prescribed (one-off prescriptions). The least frequently prescribed were mostly alternatives to the main drugs, while a few others were to exert other pharmacologic actions, different from those specified in Table 2. Classes of drugs in Table 3 which are not found in Table 2 are antacids, rehydrating agent, sedatives and topical applications. For the least prescribed drugs listed in Table 4, the types of drugs not included in Table 2 and Table 3 are anihelminthics, appetizer, anti-scabies and anti-flagyllate.

As shown in Table 4, the majority of the miscellaneous drugs were also anti-malarials, antibiotics, haematinics, anti-histamines or anti-inflammatory drugs and analgesics. Others used with relatively less frequency were the cough mixtures for upper respiratory tract infections, antacids and anti-helminthics.

Figure 1 gives a summary of the number of drugs for each group of the various pharmacological agents. The anti-malarials were the most varied, made up of 14 different drugs, followed by the antibiotics of 11 types. The least varied were the anti-inflammatory for which there were only 7 brands. In all, there were 18 miscellaneous drugs.

\section{Discussion}

The drugs prescription, in the main, was uniform in the sense that the patients of both sexes of all the SCD genotype were given drugs to cater for similar aberrant phenotypic expressions. Thus, there were the drugs to take care of pain and accompanying inflammation (analgesics and anti-inflammatory drugs), anti-malarial drugs and antibiotics.

Table 2. The most commonly prescribed drugs based on pharmacological action.

\begin{tabular}{cc}
\hline Analgesics/narcotics & Anti-malarials \\
\hline Paracetamol & Daraprim Ibup \\
Morphine & Artes/amdq \\
& Camoquin \\
Anti-inflammatory & Antibiotics \\
Ibuprofen & Penicillin V \\
Diclofenac & Amoxicillin \\
& Ciproflox \\
Vitamin suppl' & Amoxiclav \\
Folic acid & Mineral suppl' \\
B-complex & Bencozinc \\
\hline
\end{tabular}

Ibup: ibuprofen; artes: artesunate; amdq: amodiaquin; suppl': supplement. 
Table 3. Drugs less frequently prescribed (2 - 9 times).

\begin{tabular}{ccc}
\hline & Type of drug & \\
Anti-malarial & Antibiotic \\
Amodiaquin 5 & Flucloxacin 9 \\
Proguanil 4 & Zinnat 3 \\
Artemos 3 & \\
Analgesic & Haematinic \\
Parafin forte 6 & Fersolate \\
DF 118 2 & \\
Pethidine 4 & Sedative \\
Glucosamine 2 & Amytal 3 \\
Trumadol 2 & \\
Antacid & Anti-histamine \\
Mg trisilicate 2 & Cetrizine 3 \\
Topical application & Vit suppl \\
Germidine cream 2 & Multivite 3 \\
Workadine ointment 2 & \\
Rehydrating agent & \\
Oral rehydrating salt 2 & \\
\hline
\end{tabular}

Vit suppl': vitamin supplement.

Table 4. Occasional prescriptions (one-off prescriptions).

\begin{tabular}{|c|c|}
\hline \multicolumn{2}{|c|}{ Type of drug } \\
\hline Anti-malarials & Antibiotics \\
\hline Alaxin & Augmentin \\
\hline Nivaquin 442 & Doxacillin \\
\hline Coarsucan & Erythromycin \\
\hline \multirow[t]{2}{*}{ Fansidar } & Chlorampenicol \\
\hline & Gentamicin \\
\hline Analgesic & Haematinic \\
\hline Nalcofen & Fex up R \\
\hline Nimsulide & MB forte \\
\hline \multirow[t]{2}{*}{ Toradol } & Fofax \\
\hline & Ciclavit \\
\hline Antacid & Anti-histamine \\
\hline Gastracid & Phenergan \\
\hline \multirow[t]{3}{*}{ Nugel } & Rhizin \\
\hline & Piriton \\
\hline & Neodeva \\
\hline Cough mixture & Antihelmintic \\
\hline Mucolex & Zentel \\
\hline \multicolumn{2}{|l|}{ Berylin cough mixture vermox } \\
\hline \multicolumn{2}{|l|}{ Sedalyn cough mixture } \\
\hline \multicolumn{2}{|l|}{ Zedek } \\
\hline Sedative & Appetiser \\
\hline Diazepam & Lysatone \\
\hline Intestinal antiflagylate & Anti-scabies \\
\hline Metrolex & Tetmosol \\
\hline
\end{tabular}




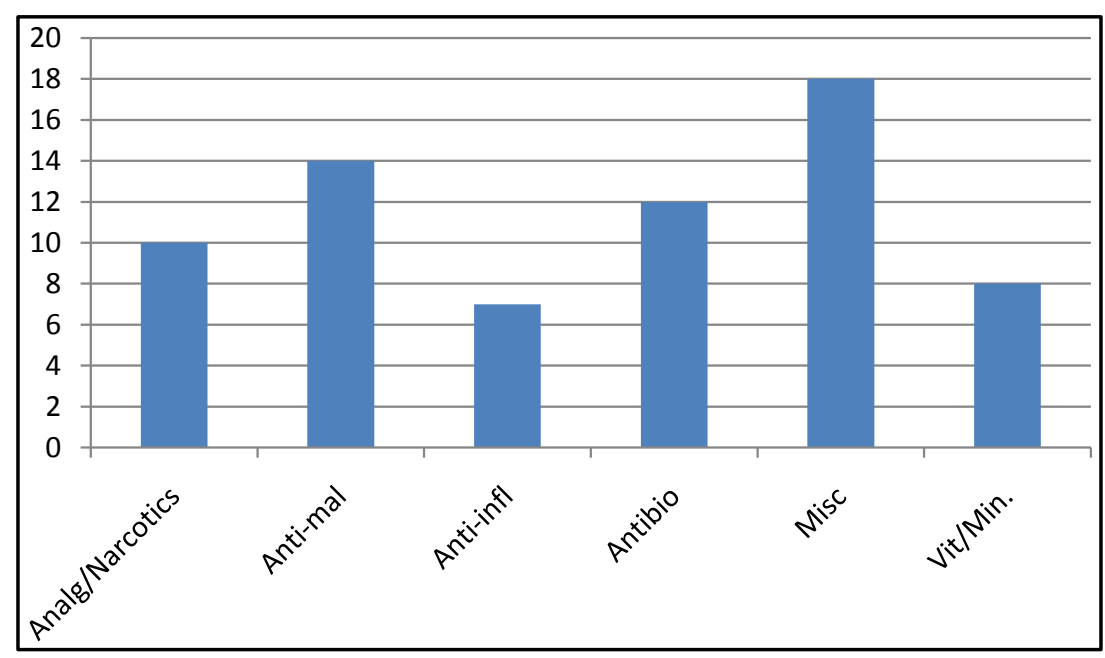

Figure 1. Different classes of drugs used by SCD subjects. Analg: analgesics; anti-mal: anti-malaria; anti-infl: anti-inflammatory; vit/min: vitamin/mineral; misc: miscallaneous.

A closer study of the list of 18 frequently prescribed drugs in Table 1 can help in delineating four main therapeutic targets. First, folic acid, B-complex, zincovit/bencovit, providing vitamin and mineral supplementation to counteract the continuous haemolysis of red cells, and to prevent growth deficit; second, paracetamol, diclofenac, ibuprofen and morphine as pain-killing and anti-inflammatory agents. Third, penicillin V, amoxicillin, ciprofloxacin, amoxiclav serve as antibiotics, providing a broader spectrum of action; and fourth, plasmotrium, daraprim, artesunate and camoquin serve as anti-malarial drugs.

Most of the less commonly prescribed drugs, as well as the occasionally prescribed drugs could be alternatives that could be used for one or two of the outlined functions, or they could complement these function. For example, if in spite of taking folic acid, B-complex and zincovit, a patient was still anaemic, then a haematinic, could be prescribed, examples being fersolate, MB forte.

Being two anti-inflammatory analgesics, diclofenac and ibuprofen were not prescribed concurrently to patients. Both are non-steroidal anti-inflammatory drugs, which have the ability to reduce the synthesis of prostangladins and leukotrienes, but whereas Ibuprofen is a derivative of phenyl propanoic acid, diclofenac is a derivative of phenylacetic acid [9]. Diclofenac is a potent cyclooxygenase inhibitor, with anti-inflammatory, analgesic and antipyretic properties [10].

Daraprim is pyrimethamine, a known inhibitor of dihydrofolate reductase of malaria parasites. Penicillin V is a narrow spectrum $\beta$-lactam antibiotic, which has the advantage of being administered orally.

The inclusion of folic acid in the routine drug regimen is in the light of SCD patients having higher physiological requirements for folic acid due to accelerated erythropoiesis [11]. Therefore, such patients are given folic acid supplementation, the rationale being to prevent the deficiency caused by increased folate turnover in chronic haemolytic anaemia [12]. The use of folate by SCD persons has been uncertain. According to Yardumian and Crawley [13], even when dietary intake is sufficient, there can be increased homocysteine that can contribute to hypercoagulability, which can be prevented through folate administration. Daraprim is taken as a prophylaxis against malaria infection, and penicillin $\mathrm{V}$ is an antibiotic, particularly against gram positive bacteria. Where patients use mosquito nets, daraprim was not prescribed to them, as mosquito bites, through which schizonts were introduced to human host were prevented.

Varying drug regimen were used to treat symptomatic malaria fever. At present, the first line treatment for malaria is a combination of amodiaquin and artesunate. However, before this combination therapy was adopted by Ghana's Ministry of Health in 2005, some prescriptions based on monotherapies of amodiaquin, artesunate and other anti-malarials like camoquin and plasmotrium were given. Other less commonly used anti-malarials were proguanil, artemos, alaxin and camosunate. In a Kenyan study, the anti-malarial prophylaxis used was proguanil [14].

Yet another group of commonly used drugs were those containing zinc supplements, particularly zincovit, and 
to a small extent, bencozinc. In SCD, there is inefficient protein utilization, which could be partially linked to zinc deficiency, as about $60 \%$ - 70\% of adolescent and adult SCD subjects are zinc deficient [15]. Increased haemolysis releases a considerable amount of zinc, which circulates in the plasma pool, but substantial amount get lost through urine, increasing the daily requirement for zinc [16].

Vaso-occlusive crisis, characterized by pain and inflammation is the hallmark of SCD [3]. The treatment of inflammation involves two primary goals; first, the relief of pain, which is often the presenting symptom and the major continuing complaint of the patient, and second, the slowing or arrest of the tissue-damaging process [8]. Reduction of inflammation with anti-inflammatory drugs often results in relief of pain for significant periods.

The non-sterodal anti-inflammatory drugs (NSAIDs) are anti-inflammatory, antipyretics and analgesics, and are also used for osteoarthritis, rheumatoid conditions and other joint disorders [17]. The two most commonly used were diclofenac and ibuprofen, but the less commonly prescribed were naproxyn and nimesulide. For mild pain, paracetamol or acetaminophen, an aniline-derived analgesic-antipyretic [10] is recommended. For more severe pain, however, opiods like morphine and pethidine (mepiridine) were given as injections. Morphine and pethidine are narcotics, with morphine being a derivative of some white poppy plants, while pethidine is a synthetic drug [17]. The main problem with the use of the narcotics is the likelihood of developing psychological and physical dependence.

Apart from penicillin V, other antibiotics used were flucloxacillin (fluclox and amoxicillin), ciprofloxacin, gentamycin and augmentin. fluclox and amoxacillin are semi-synthetic penicillin; cipro is a 4-quinolone, gentamycin, an aminoglycoside, while augmentin is a physical mixture of clavulinic acid and amoxicillin [10]. The other antibiotics were erythromycin, chloramphenicol and zinnat (cefuroxime).

Some of the other drugs and their mode of action are as follows; zentel (containing albendazole) for intestinal parasites, some cough mixtures like zedex, sedalyn and berylin, for respiratory tract infections. To take care of cases of hypersecretion of $\mathrm{HCl}$, antacids like gastracid, acinil (cimitidine) were prescribed. Urticaria, skin rashes and other allergies were treated with rhizin (cetrizine), tetrasil, piriton, as well as some topical preparations like wokadine ointment and germidine cream. The use of neodeva eye cream was for an opthamological problem.

From Figure 1, the anti-malarials and antibiotics were the most varied drugs, while the anti-inflammatory and vitamin/mineral supplements were the least varied. Some of the anti-malarials were different brand names but the same active ingredient(s). Other reasons for the variation could be the problem of resistance developed by the microbial pathogen, pharmacogenetics and drug idiosyncracy of the patients. Resistance to the various anti-malarial drugs and antibiotics is common. Indiscriminate use of antimicrobial therapy can lead to an increase in antibiotic resistance, resulting in the use of alternative and more costly therapies [18]. The way individuals metabolise drugs also differ, leading to inter-individual responses to these anti-malarials. For some unknown reasons, some people show adverse reactions towards some drugs.

On the other hand, there is no problem of resistance associated with the use of the anti-inflammatory agents and the vitamin/mineral supplements, and in some cases, there are no alternatives; for example folic acid. Thus the number of choices for these drugs is more relatively limited.

In a study in UK [8], the management of acute complications consisted of blood transfusion (including exchange transfusion), prophylaxis with folate, penicillin and immunization with pneumovax II. Pain was managed with various opiates and NSAIDS; different antibiotics for infections and inhibitors of angiotensin-converting enzymes for renal complications.

An earlier account on the management of SCD patients by Konotey-Ahulu at the Korle Bu Teaching Hospital in Accra [19], our country's capital, share common features in the classes of drugs, but there were some few differences. Chloroquin and proguanil were the two key anti-malarials recommended by Konotey-Ahulu. While the use of chloroquin has been discontinued, proguanil is sparsely used. Common analgesics used in the Accra study were indomethacin, paracetamol and promazine. It is also worth noting that the Accra study was in the 90’s, while the present study was specifically between October 2006 and November 2007; the over two decades between the two studies could have accounted for some of the differences in the drugs used.

Pathophysiologically, morbidity in SCD results from sickling, dehydration of red cells, inflammation, adhesivity to the endothelium and pro-coagulant state [6]. For the developed countries, the use of hydroxyurea has been shown to overcome many of these problems. Additionally, prophylactic penicillin and folic acid and immunization against pneumococcal infections, as well as blood transfusions are part of the supportive management measures.

In our setting, this study has shown that the SCD patients also use folic acid and penicillin, together with an- 
ti-malarial prophylaxis. They also use pain-relieving and anti-inflammatory agents, while those who develop malaria used the appropriate prescribed therapies.

What is unique in our report is the ranking of the commonly used drugs by SCD subjects in a tropical environment in which the well known vaso-occlusive pathology is aggravated by malaria and other infections.

\section{Conclusion}

This retrospective study of drug prescription pattern for SCD patients, covering a twelve-month period in a tropical environment has shown folic acid prophylaxis as the most common prescription, followed by diclofenac, an analgesic NSAID drug. Other important drugs were daraprim for malaria prophylaxis and artesunate/ amodiaquin and a range of symptomatic anti-malarial drugs. Some commonly used antibiotics were penicillin V and amoxicillin. The study has therefore, shown that the well-being of SCD patients in a typical tropical terrain, depends on haematinic vitamin/mineral supplements, anti-malarials, analgesics/anti-inflammatory/antipyretics and antibiotics.

\section{References}

[1] Bonds, D.R. (2003) Three Decades of Innovation in the Management of Sickle Cell Disease: The Road to Understanding the Sickle Cell Disease Phenotype. Blood Reviews, 19, 99-110. http://dx.doi.org/10.1016/j.blre.2004.04.002

[2] Dampier, C. and Setty, B.N.Y. (2004) Vaso-Constriction in Children with Sickle Cell Disease: Clinical Characteristics and Biologic Correlations. Journal of Pediatric Hematology/Oncology, 29, 785-790.

[3] Benjamin, L.J. (2001) The Nature and Management of Acute Pain Episode in Sickle Cell Disease. In: Forget, B.G., Higgs, D., Nagel, R.L. and Steinberg, M.H., Eds., Diseases of Hemoglobin, Cambridge University Press, Cambridge, 671-710.

[4] de Franceschi, L., Finco, G., Vassanelli, A., Zaia, B., Ischia, S. and Corrocher, R. (2004) A Pilot Study on the Efficacy of Ketorolac plus Tramadol Infusion Combined with Erythrocytapheresis in the Management of Acute Severe VasoOcclusive Crises and Sickle Cell Pain. Haematologica, 489, 1389-1391.

[5] Krisnamoorthy, P., Alyaarubi, S., Abish, A., Gale, M., Abuquerque, P. and Jabado, N. (2006) Primary Hyperparathyroidism Mimicking Vaso-Occlusive Crises in Sickle Cell Disease. Journal of Pediatrics, 118, e537-e539. http://dx.doi.org/10.1542/peds.2006-0337

[6] Aliyu, Z.K., Tumblin, A.R. and Kato, G.J. (2006) Current Therapy of Sickle Cell Disease. Haematologica, 91, 7-10.

[7] Jison, M.L., Munson, P.J., Barb, J.F., Suffredini, A.F., Talwar, S., Logun, C., Raghavachori, N., Beigel, J.H., Danner, R.L. and Gladwin, M.T. (2004) Blood Mononuclear Cell Gene Expression Profiles Characterize the Oxidant, Hemolytic, and Inflammatory Stress in the Expression of Sickle Cell Disease. Blood, 104, 270-280. http://dx.doi.org/10.1182/blood-2003-08-2760

[8] Hankins, J. and Aygun, B. (2009) Pharmacotherapy in Sickle Cell Disease-State of the Art and Future Prospects. British Journal of Haematology, 145, 296-308. http://dx.doi.org/10.1111/j.1365-2141.2009.07602.x

[9] Payan, D.G. and Katzung, B.G. (1992) Nonsteroidal Anti-Inflammatory Drugs: Nonopioid Analgesics; Drugs Used in Gout. In: Katzung, B.G., Ed., Basic and Clinical Pharmacology, 6th Edition, Appleton and Lange, Norwalk, Connecticut, 535-557.

[10] Gringauz, A. (1997) Introduction to Medicinal Chemistry. Wiley-VCH, New York, 144,205,235,251,265-266.

[11] Lindenbaum, J. and Klipstein, F.A. (1963) Folic Acid Deficiency in Sickle Cell Disease. New England Journal of Medicine, 269, 875-882. http://dx.doi.org/10.1056/NEJM196310242691701

[12] Lindenbaum, J. (1997) Workshop on Human Folate Requirements Folic Acid Biochemistry and Physiology in Relation to Human Nutritional Requirement. National Academy of Sciences, Washington DC, 256-276.

[13] Yardurmian, A. and Crawley, C. (2001) Sickle Cell Disease. Clinical Medicine, 1, 441-451. http://dx.doi.org/10.7861/clinmedicine.1-6-441

[14] Sadarangani, M., Makani, J., Komba, A.N., Ajala-Agbo, T., Newton, C.R., Marsh, K. and Williams, T.N. (2009) An Observational Study of Children in Kilifi, Kenya. British Journal of Haematology, 146, 675-682. http://dx.doi.org/10.1111/j.1365-2141.2009.07771.x

[15] Prasad, A.S. (1993) Clinical Spectrum of Human Zinc Deficiency. In: Prasad, A.S., Ed., Biochemistry of Zinc, Plenum, New York, 219-258. http://dx.doi.org/10.1007/978-1-4757-9444-1 11

[16] Prasad, A.S. (1997) [Editorial] Malnutrition in Sickle Cell Disease Patients. American Journal of Clinical Nutrition, 66, 423-424.

[17] Lambright-Eckker, J.A. and Stimmel-Fair, J.M. (1996) Pharmacology Essentials. WB Saunders Company, Philadel- 
phia, 179,207.

[18] World Health Organisation (2003) The Africa Malaria Report. http://www.afro.who.int

[19] Konotey-Ahulu, F.I.D (1991) The Sickle Disease Patient. Macmillan, London. 
Scientific Research Publishing (SCIRP) is one of the largest Open Access journal publishers. It is currently publishing more than 200 open access, online, peer-reviewed journals covering a wide range of academic disciplines. SCIRP serves the worldwide academic communities and contributes to the progress and application of science with its publication.

Other selected journals from SCIRP are listed as below. Submit your manuscript to us via either submit@scirp.org or Online Submission Portal.
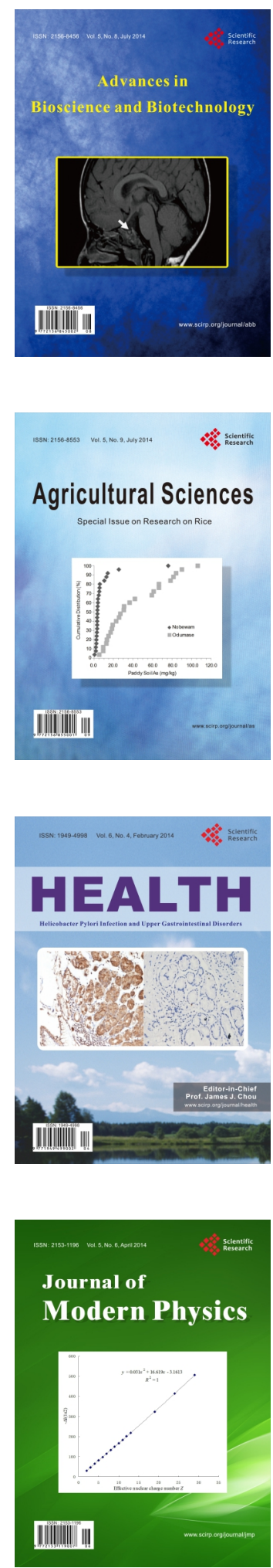
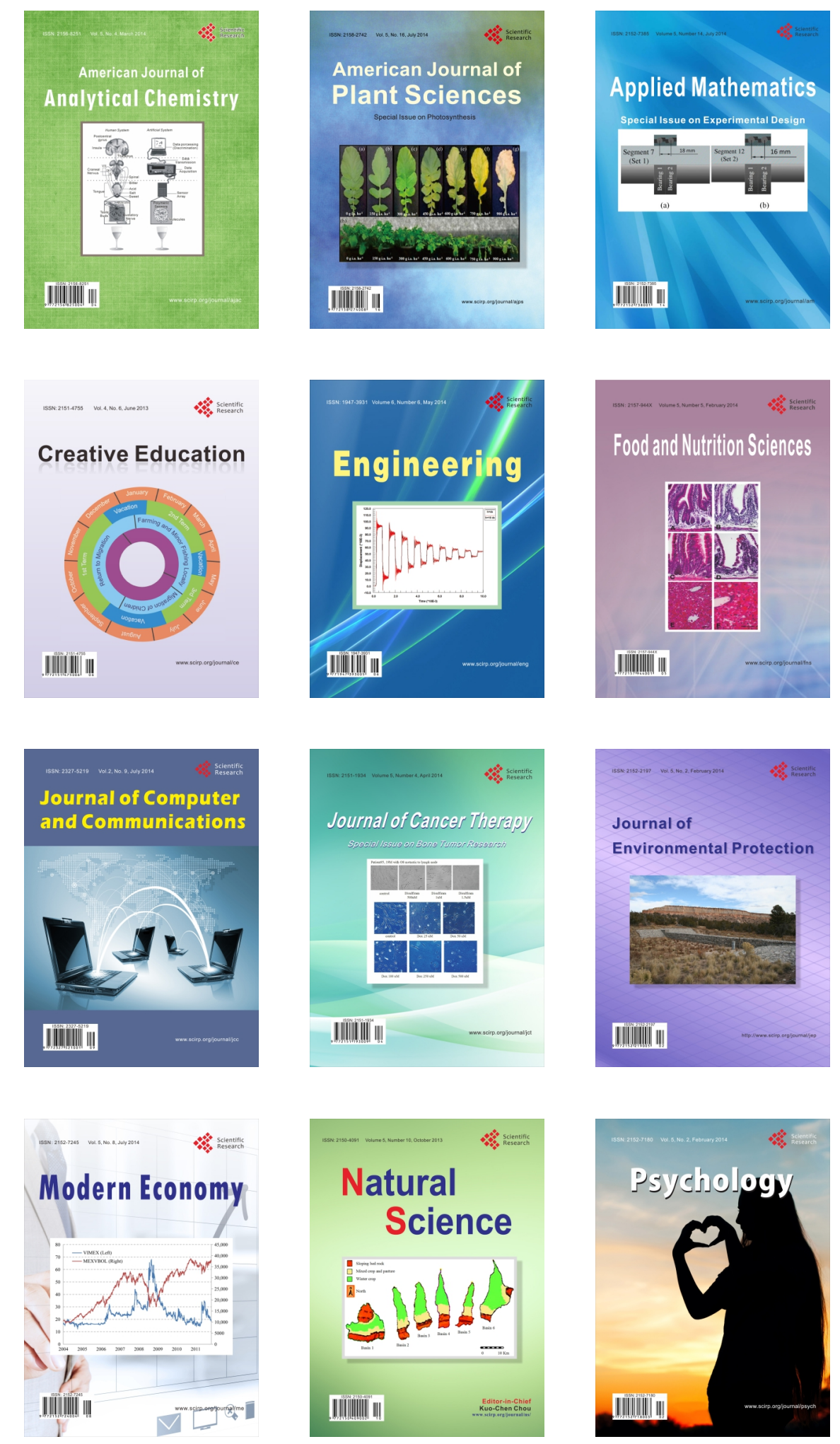